\title{
An isotopic study of the role of carbon dioxide in outbursts in coal mines
}

\author{
J. W. Sмith and K. W. Gould \\ CSIRO Fuel Geoscience Unit, P.O. Box 136, North Ryde, NSW, Australia 2113 \\ (Received November 1, 1979; accepted February 19, 1980)
}

\begin{abstract}
The occurrence of instantaneous outbursting in the Bulli coal seam at the West Cliff Colliery, Appin, NSW can be correlated directly with an increase in concentration $(0.5$ to $75 \%)$ and a related decrease in the ${ }^{13} \mathrm{C}$ content $\left(\delta^{13} \mathrm{C}+16\right.$ to $-8 \%$ PDB $)$ of the $\mathrm{CO}_{2}$ in the seam gas. Two sources of $\mathrm{CO}_{2}$ are required.

The greater incidence of outbursting in $\mathrm{CO}_{2}$-rich zones is explained by the conversion to bicarbonate of cleat and fracture filling calcite deep within the coal and the transport of this bicarbonate in water to mine openings. The weakening of the resistance of the coal to shear by this removal of carbonate is an additional factor to be considered in assessing outbursting situations.
\end{abstract}

\section{INTRODUCTION}

An increasing demand for coal, as a result of changes in the availability and cost of other fossil fuels, has re-focussed attention on the problem of outbursting in deeper coal mines. When the rate of advance of the cutting face is slow, better opportunities for the slow escape of the gases under high pressure in the virgin coal exist. However, at the faster rates of advance of the coal face now required, less time is available for the equalization of gas pressures and mininginduced stresses. Thus the hazard of instantaneous outbursting of gas and coal is increased, although under favourable circumstances some control may be achieved by gas drainage.

It is generally assumed that the pressure and volume of gases held within the virgin coal play a major part in producing outbursts, however, some doubt still exists as to whether outbursts are actually 'triggered' by gas pressures or by stresses induced in the rock itself during mining operations.

The possible effects of coal gassiness and gas pressures, the sorptive/desorptive capacities of coals for methane and carbon dioxide, and methods available for translating this evidence into practical terms have been fully discussed and reviewed by HARGRAVES (1958, 1962, 1966, 1973) and Patching (1970). Amongst HARGRAVES findings is the recognition that, on occasion, violent outbursts in deeper Australian coal mines may be largely confined to regions, or mine sections, in which the carbon dioxide content of the seam gas is high, a factor also reported in coal mining operations in parts of France and Poland (RICE, 1931; Wilson, 1931; STUTZER, 1936).

High concentrations of carbon dioxide in seam gases in Australian coals occur in regions of igneous activity and associated faulting and this component has been described as being of presumed pneumatolytic origin (HARGRAVES, 1973). However, no generally acceptable special role has yet been assigned to carbon dioxide in effecting outbursting.

Carbonic acid has the capacity to convert calcite to bicarbonate, the form in which this species is readily transported in carbon dioxiderich water. Whether such reactions occur to a significant extent in coal mines has yet to be shown, but such an interaction and the subsequent removal of calcite originally filling cleats and fractures in the coal may be envisaged as 
reducing the resistance of the coal to shear and thus promoting outbursting.

Previous and continuing isotopic studies in this laboratory of the carbonates associated with Australian coals (SMITH, 1978; Gould and SMITH, 1979) appear to throw some light on this issue.

In apparently normal Permian bituminous coals, when significant secondary calcite concentrations resulting from coal maturation reactions occur in cleats, this calcite is generally characterized by a remarkably high ${ }^{13} \mathrm{C}$ content $\left(\delta^{13} \mathrm{C}\right.$ values to $+30 \%$ PDB have been measured). In fact, calcites with $\delta^{13} \mathrm{C}$ values of $<0 \%$ PDB are rarely seen, and then, usually only in very low concentrations.

It is therefore particularly interesting to find that where coals are visibly heat altered, and often where coals only occur in regions of known or even suspect igneous activity (e.g. Bowen Basin, Queensland), 'heavy' calcites are commonly absent. This absence possibly results from interaction with carbonic acid to form bicarbonate. In fact, only 'light' calcites occur, often in low concentrations (Gould and SMITH, 1979). However, several notable exceptions to this trend have been seen.

In view of these and other results, a broad survey of the stable isotope geochemistry of Australian coals and associated fluids and minerals has been commenced with the objectives of providing (1) further information on the causes of outbursting, (2) comparative data for use in natural gas exploration. In particular, the West Cliff Colliery at Appin in the Southern Coalfields of the Sydney Basin, NSW, has been selected as the site for a preliminary detailed study designed to identify those factors relating seam gas composition to outbursting. At West Cliff, carbon dioxide concentrations in the seam gas are variable and have been reported to be high in those sections where faulting and a tendency to outbursting are more pronounced (ShePherd and CREASEY, 1979).

\section{EXPERIMENTAL}

at 17 sites from the Bulli Seam at West Cliff Colliery. Gases together with any accompanying waters were taken from $40 \mathrm{~mm}$ diameter holes drilled to a depth of 2-3 m into the virgin coal. When available, coal samples containing calcite were taken in the vicinity of each gas sampling some light site.

Analytical procedures An initial chromatographic analysis of the gases showed the absence of hydrocarbons other than methane. Therefore the gas components were conveniently separated PDB and measured and the methane combusted to carbon dioxide in a modified version of the PDB apparatus of SAKAI et al. (1976).

Aliquots of mine water were acidified with phosphoric acid and the liberated carbon dioxide was measured manometrically after purification and drying.

Calcite samples were reacted with $100 \%$ phosphoric acid by the method of MCCREA (1950) and the liberated carbon dioxide was measured as before after drying and purification.

${ }^{13} \mathrm{C} /{ }^{12} \mathrm{C}$ ratios in the carbon dioxide were determined on a Micromass 602 mass spectrometer. Measured ratios were converted to $\delta^{13} \mathrm{C}$ values by the following equation,

$$
\begin{aligned}
\delta^{13} \mathrm{C} \% \text { PDB }=\frac{{ }^{13} \mathrm{C} /{ }^{12} \mathrm{C}_{\text {unknown }}-{ }^{13} \mathrm{C} /{ }^{12} \mathrm{C} \text { PDB }}{{ }^{13} \mathrm{C} /{ }^{12} \mathrm{C} \text { PDB }} \\
\times 10^{3}
\end{aligned}
$$

and corrected according to CRAIG (1957).

Cations dissolved in mine waters were determined by direct comparison with standards using flame atomic absorption.

The rate of attack of carbon dioxide on calcite in an actual mine specimen was established as follows. A lump sample of coal from the Young Borehole Seam displaying a prominent fracture was encased in polyester resin and cut with a diamond saw to provide two "mirror image' slices of coal. These were photographed and then immersed in separate water-filled containers at $22^{\circ} \mathrm{C}$; carbon dioxide was bubbled continuously through one and nitrogen through the other. After 5 days the specimens were 
Table 1. Concentrations and isotopic compositions of carbon-containing species collected at West Cliff Colliery

\begin{tabular}{|c|c|c|c|c|c|}
\hline \multirow{2}{*}{$\begin{array}{l}\mathrm{CO}_{2} \text { content of } \\
\text { seam gas* } \\
(\% \mathrm{v} / \mathrm{v} \text {, air free })\end{array}$} & \multirow{2}{*}{$\begin{array}{l}\text { Bicarbonate } \\
\text { concentration of } \\
\text { seam water } \\
\left(\mathrm{ppm} \mathrm{HCO}_{3}\right)\end{array}$} & \multicolumn{4}{|c|}{ Carbon isotope ratios $\left(\delta^{13} \mathrm{C} \% 0\right.$ PDB $)$ of Bulli Seam materials } \\
\hline & & $\delta^{13} \mathrm{C}$ of $\mathrm{CO}_{2}$ in & $\begin{array}{l}\delta^{13} \mathrm{C}_{\text {of }} \mathrm{HCO}_{3}^{-} \text {in } \\
\text { seam water }\end{array}$ & $\begin{array}{l}\delta^{13} \mathrm{C} \text { of } \mathrm{CH}_{4} \text { in } \\
\text { seam gas }\end{array}$ & $\begin{array}{l}\delta^{13} \mathrm{C} \text { of calcites } \\
\text { in coal cleaots } \dagger\end{array}$ \\
\hline 0.5 & & +13.7 & & -54.8 & \\
\hline 0.8 & 4255 & +15.7 & +22.3 & -46.9 & +17.3 \\
\hline 1.0 & & +10.8 & & -56.1 & +16.3 \\
\hline 1.0 & & +6.5 & & -55.3 & +14.8 \\
\hline 1.2 & & +6.5 & & -56.8 & \\
\hline 1.3 & & +5.4 & & -58.0 & \\
\hline 2.8 & & +0.8 & & -54.5 & \\
\hline 3.9 & 6322 & +0.5 & +8.4 & -50.4 & \\
\hline 6.0 & 7211 & -4.8 & +2.6 & -57.6 & \\
\hline 6.5 & & -5.6 & & -56.1 & \\
\hline 7.0 & & -1.8 & & -57.8 & \\
\hline 12.0 & & -8.6 & & -55.1 & \\
\hline 16.2 & & -10.7 & & -58.6 & \\
\hline 20.2 & & -10.0 & & -58.1 & \\
\hline 24.6 & 7269 & -5.6 & +2.8 & -53.4 & \\
\hline 50.5 & & -7.0 & & -54.1 & \\
\hline 75.0 & & -7.2 & & -52.3 & \\
\hline
\end{tabular}

* Seam gases consisted of $\mathrm{CO}_{2}, \mathrm{CH}_{4}$ and traces of air only.

$\dagger$ The three calcites examined could not be related to specific gas sampling points but were taken from the mine area in which the seam gas contained less than $2 \% \mathrm{v} / \mathrm{v} \mathrm{CO} \mathrm{CO}_{2}$.

removed, dried, examined and re-photographed. Cations dissolved in the water were also determined.

\section{RESULTS}

The chemical composition of seam gases and the $\delta^{13} \mathrm{C}$ values of carbon dioxide and methane in seam gases, bicarbonate in solution in mine waters and calcite are shown in Table 1 . Water was only collected with the gas at four sites. Calcite was not seen at all in areas of high carbon dioxide concentration. It appeared not to be common in other sections and the samples taken were often considerably removed from, and difficult to relate to, actual gas sampling points.

Table 1 shows clearly that with increasing carbon dioxide concentrations in seam gases the ${ }^{13} \mathrm{C}$ content of the carbon dioxide decreases progressively. This information is also shown graphically in Fig. 1 together with a theoretical mixing curve for the dilution of seam gas carbon. dioxide (concentration $0.6 \%, \delta^{13} \mathrm{C}$ value $+20 \%$ o PDB) with externally produced carbon dioxide $\left(\delta^{13} \mathrm{C}\right.$ value $-8 \%$. Variations in seam gas composition do not occur at random within the mine but $\mathrm{CO}_{2}$ concentrations increase and $\mathrm{CO}_{2}$ $\delta^{13} \mathrm{C}$ values decrease, according to Fig. 1 , as the proposed external source of the carbon dioxide

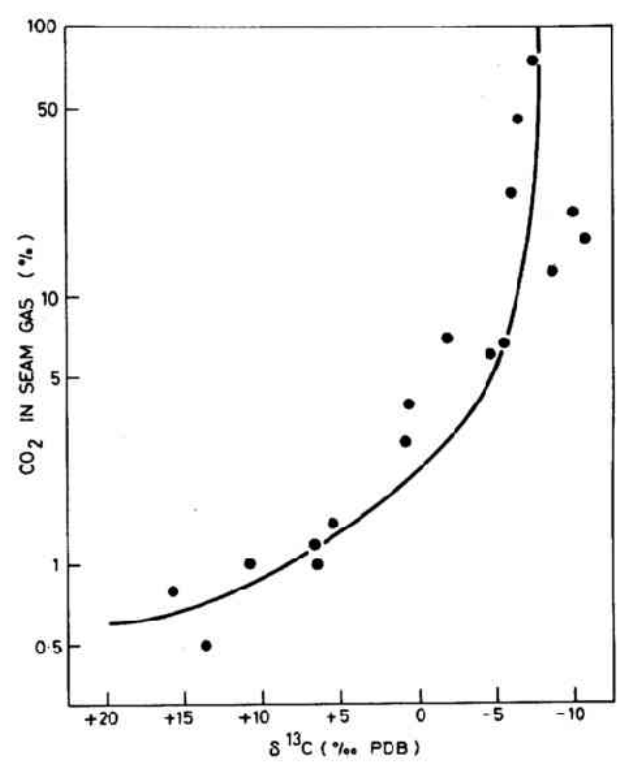

Fig. 1 Isotopic composition of carbon dioxide relative to concentration of carbon dioxide in seam gas of West Cliff Colliery ( $\bullet)$. The theoretical mixing curve for dilution of seam gas $\mathrm{CO}_{2}\left(\delta^{13} \mathrm{C}+20 \%\right.$ ) with externally produced $\mathrm{CO}_{2}\left({ }^{13} \delta \mathrm{C}-8 \%\right.$ o) is shown. 
is approached.

If the single $\delta^{13} \mathrm{C}$ value of $-46.9 \%$ PDB is rejected as probably being erroneous, the $\delta^{13} \mathrm{C}$ value for methane remains relatively constant at $-55.6 \pm 2.3 \%$ PDB in spite of the major variations in the concentration of associated carbon dioxide. Consequently isotopic exchange between these gases must be regarded as minimal and certainly insufficient to alter the isotopic compositions of either component measurably.

The differences in ${ }^{13} \mathrm{C}$ contents between bicarbonate and carbon dioxide gas collected at particular sites range from +6.6 to $+8.4 \%$ PDB with an average $\triangle^{13} \mathrm{C}\left(\mathrm{HCO}_{3}\right.$ aq $-\mathrm{CO}_{2}$ gas $)$ value of $+7.6 \%$. This isotopic difference compares very well with the value of $+8.0 \%$ predicted by FrIEDMAN and O'NeIL (1977) for isotopic equilibrium fractionation between bicarbonate in solution and carbon dioxide gas at $25^{\circ} \mathrm{C}$.

The $\delta^{13} \mathrm{C}$ values found for the three calcites from sections where the carbon dioxide content of the seam gas is low are also generally consistent with the establishment of isotopic equilibrium between these and the variably ${ }^{13} \mathrm{C}$ enriched carbon dioxide in these regions (Friedman and O'NeIl, 1977).

Major cations in total water extracts of the lump coal specimens from the Young Borehole seam are listed in Table 2. The much higher concentrations of alkaline-earth metals found in the water through which carbon dioxide had been passed are strong indications of the solution of calcite. The photographs in Fig. 2

Table 2. Cations in total water extracts of coal from Young Borehole seam ( $\left.\mu \mathrm{g}^{*}\right)$

\begin{tabular}{crrrrr}
\hline \hline Gas passed & $\mathrm{Fe}$ & $\mathrm{Na}$ & $\mathrm{Mg}$ & $\mathrm{Ca}$ & $\mathrm{Sr}$ \\
\hline $\mathrm{N}_{2}$ & 1 & 400 & 40 & 760 & 7 \\
$\mathrm{CO}_{2}$ & 86 & 470 & 160 & 5300 & 53 \\
\hline
\end{tabular}

* The 'slices' of coal used were of the same cross section $(40 \mathrm{~mm} \times 70 \mathrm{~mm})$ with a thickness of $5 \mathrm{~mm}$. Precise weights of the coal in each slice could not be determined owing to these being encased in resin. Accordingly the comparison of extracts is made on the basis of total soluble cations ( $\mu \mathrm{g})$.
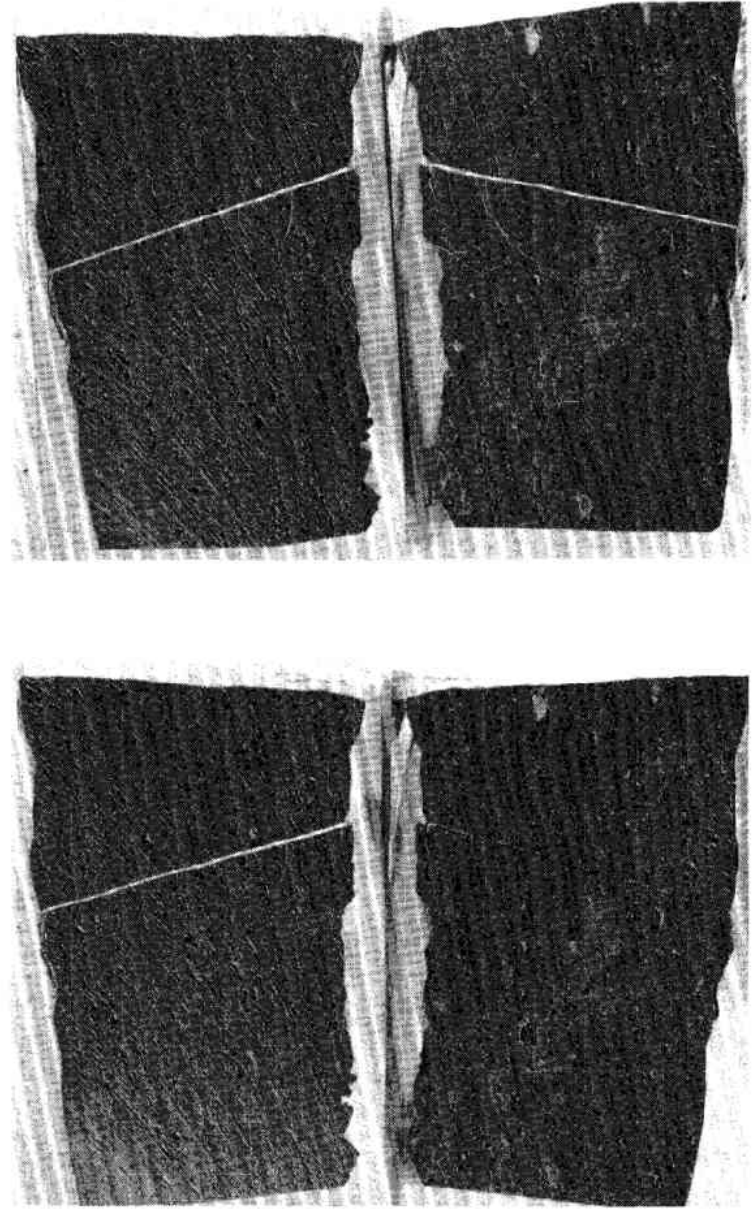

Fig. 2. (a) and (b) 'Mirror image' slices of Young Borehole coal.

(c) Coal slice 2(a) after immersion in water and passage of $\mathrm{N}_{2}$ for 5 days.

(d) Coal slice 2(b) after immersion in water and passage of $\mathrm{CO}_{2}$ for 5 days.

clearly demonstrate this to be the case. In the control experiment where nitrogen gas was passed, no significant alteration in the mineral filling of the fracture can be seen, however, where carbon dioxide was used, the fracture filling was largely dissolved.

\section{Discussion}

Seam gas containing $<2 \%$ carbon dioxide, strongly enriched in ${ }^{13} \mathrm{C}$, can be reconciled readily with previous isotopic studies of car- 
bonates in normal coals (SMITH, 1978; Gould and SмrTH, 1979) and with the low organic oxygen content of the Bulli Seam coal ( $5 \%$ dry, ash-free basis). Such gas is therefore recognized as resulting from normal maturation processes.

Both the isotopic composition and volume of the 'lighter' carbon dioxide are inconsistent with the coal being the source for this gas. Rather they indicate a probable igneous source, a likely origin in view of the local igneous activity, although a major contribution of atmospheric carbon dioxide in meteoric waters is not isotopically prohibited. Indeed, from the strong association between the outbursting of gas and coal and faulting at West Cliff Colliery (Shepherd and Creasey, 1979), it seems that the latter may very well provide a means of access for carbon dioxide from an external source. Certainly the generally accepted $\delta^{13} \mathrm{C}$ value for carbon dioxide of igneous origin, $-7 \%$ PDB (HoEFs, 1973), agrees very well with the values reported here. Furthermore the data on the chemical and isotopic composition of the seam gases (Table 1) preclude isotopic exchange from influencing these reuslts.

The occurrence of ${ }^{13} \mathrm{C}$-enriched carbonates together with traces of correspondingly enriched carbon dioxide in the seam gas are general features of stable bituminous coal mines and mine sections. Their frequent absence in faulted, wet sections together with the appearance in these sections of very high concentrations of carbon dioxide with a greatly depleted ${ }^{13} \mathrm{C}$ content ( -8 to $-10 \%$ PDB) appear to be related events (SMITH, Gould and RigBY, in preparation).

It has been shown (Fig. 2) that, in the laboratory, calcium carbonate may be solubilized in water as bicarbonate by the passage of carbon dioxide gas. A similar solution of carbonate may be visualized in these coal mines where high concentrations of carbon dioxide exist in seam gas and water is abundant. In the zone liable to gas outbursting at the West Cliff Colliery, high concentrations of 'light' carbon dioxide occur and calcite is entirely absent, possibly as the result of the same reaction. Therefore the data presented here allow another suggestion to be made to account for the greater incidence of gas outbursting in carbon dioxide-rich zones of mines.

In terms of the problem of outbursting these data are interpreted as follows.

The development of a coal mine and the driving of additional headings or entries disturb the existing hydrostatic balance and fluids flow into the mine. In regions of igneous activity, reservoirs of carbon dioxide, water and other fluids may exist together with extensive faulting. Where mine openings approach faults, localized accelerated flows of externally derived fluids may occur and, if these flows contain carbon dioxide and water, pre-existing carbonates filling cleats and fractures deep within the virgin coal will be dissolved at depth and transported towards the working face and mine openings as bicarbonate. There, the evaporative effects of mine ventilation may cause deposition of the dissolved carbonate species.

In the absence of detailed information on the relative resistances of cleat fillings and blocky coals to shear, it does not appear improbable that removal of the former may reduce the bulk strength of the coal. Certainly some additional degree of freedom of movement will be allowed and presumably, as a result, individual blocks of coal will no longer be so firmly bonded. Consequently if all other factors remain equal, e.g. gas pressure, intrinsic coal strength, etc., the tendency to outbursting is likely to be increased under these conditions. Furthermore, since in localized regions of accelerated fluid flow the virgin coal will probably be affected to a considerable depth beyond the working face by movement of fluids towards the face, the typical, tunnel-like openings caused by outbursts may be expected.

Since the solution of carbonate in cleats was achieved in a few days in the laboratory, rapidly and water changing conditions in coal mines may also be expected, with outbursts possibly following closely behind, or even just preceding 
the penetration of the seam working face by carbon dioxide rich fluids.

\section{CONCLUSION}

It is concluded from the experimental data presented here that in studies of outbursting in carbon dioxide-rich zones of coal mines another factor to be considered in assessing the situation is the possible weakening of the coal structure by conversion of carbonate to bicarbonate and removal in solution in mine water.

\section{InDUSTRIAL APPLication}

A further possible application of the views developed here has arisen as a result of discussions with Mr. L. Griffiths of Moss Vale, NSW.

The drainage and collection of natural gases from sedimentary rocks is frequently hampered by the low permeabilities of the rocks. Amongst the methods utilised to improve gas flows by opening the sedimentary structures are fracturing and the introduction of additives under pressure. As shown above, carbonic acid is an excellent solvent for calcite. Since the occurrence of carbonates as fillings in cleats and fractures in coal is common, the introduction of carbon dioxide and water into such a system under pressure might well result in the solution of the carbonates and removal of these in the water flow as bicarbonate. The rate of release of methane from coal opened in this manner would be expected to be considerably increased.

In order to produce a saleable product, separation of excessive carbon dioxide from natural gas is often required. In such circumstances, it is suggested that return of the separated carbon dioxide to the sedimentary rocks under pressure might, in itself, further promote the flow of methane by opening otherwise highly impermeable strata.

Acknowledgements-We thank the management and staff of the West Cliff Colliery, Appin, New South Wales, for their continued interest and assistance. Support was provided under the National Energy Research, Development and Demonstration Program administered by the Commonwealth Department of National Development.

\section{REFERENCES}

CraIG, H. (1957) Isotopic standards for carbon and oxygen correction factors for mass spectrometric determination of carbon dioxide. Geochim. Cosmochim. Acta 12, 133-149.

FRIEDMAN, I. and O'NEIL, J. R. (1977) Data of geochemistry. Sixth Edition, U.S. Geol. Survey Prof. Paper 440KK.

GouLD, K. W. and SMITH, J. W. (1979) The genesis and isotopic composition of carbonates associated with some Permian Australian coals. Chem. Geol. 24, 137-150.

HARGRAVES, A. J. (1958) Instantaneous outbursts of coal and gas. Proc. Australas. Inst. Min. Metall. 186, 21-67.

Hargraves, A. J. (1962) Gas in face coal. Proc. Australas. Inst. Min. Metall. 203, 7-44.

HARGRAVES, A. J. (1966) Some aspects of seam gas. School of Mines, University of West Virginia, August.

HARgraves, A. J. (1973) Planning and operation of gaseous mines. C.I.M. Bull. 66 (731), 119-128.

HOEFS, J. (1973) Stable isotope geochemistry, Springer-Verlag, 63-64.

MCCREA, J. M. (1950) On the isotope chemistry of carbonates and a paleotemperature scale. Earth Planet. Sci. Lett. 19, 373-376.

PATCHING, T. H. (1970) The retention and release of gas in coal - a review. C.I.M. Bull. 63 (703), 1302-1308.

RICE, G. S. (1931) Introductory notes on origin of instantaneous outbursts of gas in certain coal mines of Europe and Western Canada. Trans. Am. Inst. Min. Metall. Eng. 94, 75-87.

SAKAI, H., SMITH, J.W., KAPLAN, I. R. and PETROWSKI, C. (1976) Micro-determinations of C, N, S, H, He and metallic $\mathrm{Fe}, \delta^{13} \mathrm{C}, \delta^{15} \mathrm{~N}$ and $\delta^{34} \mathrm{~S}$ in geologic samples. Geochem. J. 10, 85-96.

SHEPHERD, J. and CREASEY, J. W. (1979) Forewarning of faults and outbursts of coal and gas at West Cliff Colliery, Australia. Colliery Guardian Coal International 227, 13-22.

SмIтH, J. W. (1978) Carbonates - a guide to hydrocarbons. J. Geochem. Explor. 10, 103-107.

STUTZER, O. (1936) Carbon dioxide eruptions from coal seams in Lower Silesia. Econ. Geol. 31, 441452.

WILSON, P. A. C. (1931) Instantaneous outbursts of carbon dioxide in coal mines in Lower Silesia, Germany. Trans. Am. Inst. Min. Metall. Eng. 94, 88-136. 